\title{
The Impact of Rural Financial Development on the Income Gap of Rural Residents in China: An Empirical Analysis Based on Semi-parametric Additive Model
}

\author{
Li Kunming ${ }^{1}$, Zhao Hongcheng ${ }^{2}$ and Liu Xia ${ }^{1, a, *}$ \\ ${ }^{1}$ College of economics, Fujian Agriculture and Forestry University, Fuzhou, Fujian 350002, China \\ ${ }^{2}$ School of economics and management, Fuzhou University, Fuzhou, Fujian 350116, China \\ a projectfafu@163.com \\ *corresponding author
}

Keywords: Semi-parametric Additive Model; Rural Financial Development; Income Gap of Rural Residents

\begin{abstract}
Based on panel data of 24 provinces of China from 2000 to 2015, this paper uses the semi-parametric additive model to explore the impact of rural financial development on rural residents' income gap in China. The empirical results show that rural finance development has a tendency of positive influence rural residents' income gap. However, the influence presents a nonlinear ' $\mathrm{V}$ ' shape in the short term
\end{abstract}

\section{Introduction}

The boom of rural economy is closely tied to financial development. The rural finance's contributions to economy can't be restricted to the improvement of efficiency, and great attention should be paid to the fair distribution of income. The three issues of agriculture, countryside and farmers are the focus of Chinese government, but since the reform and opening-up, the gap of rural income has gradually enlarged, which makes the problem difficult to be solved well up to now. Green Cover Book of the Rural Economy published by CASS showed that the Gini coefficient in China was up to 0.3897 , close to international cordon of 0.4 in 2012. It is a significant warning that some problems will happen due to the gap of wealth if no timely action is taken. And the income gap between rich and poor farmers is also extending gradually though their living quality has been raised so far. Moreover, Lu et al.(2013) also pointed out that the problem of rural residents' income gap and the income gap between regions was more urgent than that of urban residents'. It is of great necessity to explore the relationship between rural financial development and the income gap of rural residents in China.

\section{Literature Review}

In recent years, the researches on the relationship between financial development and income gap are quite abundant, but the relevant works about rural finance development and rural residents' income gap is scanty in contrast. In many literatures, the relationship between rural finance and farmer's income is mainly analyzed from the perspectives of rural economy and rural finance, as well as rural finance and income distribution (Greenwood and Jovan, 1990; Galor and Zeira, 1993; Banerjee and Newman, 1993). Townsend (2006) argued that high-income earners were more likely to receive comprehensive financial services than low-income earners in the process of financial development, which further exacerbated the inequality of income. Through the empirical research, Galor and Zeira (1993) had found that the increase in the level of financial development would reduce the income inequality. Morduch Jonathan (2002) studied the relationship between financial development and poverty reduction with cross-country data, and found that the financial development could significantly reduce the poverty ratio and thus effectively reduce the income gap with a positive impact on low-income groups. Aghion and Bolton (1997), and Matsuyama (2000) 
believed that there was not a simple evolutionary relationship between income distribution and financial development, but they were in a changing process. On the whole, most of foreign scholars hold the view that the influence of financial development on income gap is to some extent related to the stage of financial development, but they haven't arrived at a same conclusion.

Many Chinese scholars also explored the relationship between the two from different perspectives and standpoints. Zhang (2014) showed that the utility and the scale of rural finance had a negative impact on the income gap of rural residents in China by empirical research. Zhang (2013) found that the development of rural finance had a conspicuous impact on reducing the income gap of rural residents. Sun and Feng (2014) analyzed the mechanism of action of formal and informal rural finance on the income gap of rural residents, and showed that Kuznets hypothesis could explain the influence of rural economic development on the income gap better.

It is not difficult to find that current literature mostly uses parametric model to study the influence of the development of rural finance on the income gap of rural residents. The shortcoming of parametric model is that it needs to set the parametric structure, which may cause high risks of model specification error. And it is also one of the reasons why current literature's conclusions are different. Using the semi-parametric additive model can overcome these defects above.

\section{Method}

When there are many explanatory variables and small number of samples to use, it's very easy to cause a sharp increase of variance by using a non-parametric model, which is called 'the curse of dimensionality', and will reduce the accuracy of estimation seriously. For solving the problem, Stone(1985) proposed the addictive non-parametric model. The core of this model is to estimate a multivariate function by several unary functions, which effectively avoids 'the curse of dimension'. In addition, the addictive model can also solve the difficulties of interpretation of ordinary nonparametric model. Because the influence of explanatory variables on explained variables can be observed from the fitting image of unary function directly.

Assume that $Y$ is the dependent variable, $X_{1}, X_{2}, \cdots, X_{p}$ are independent variables. And the mathematical expression of the addictive non-parametric model is:

$$
E\left(Y \mid X_{1}, X_{2}, \cdots, X_{p}\right)=\alpha+\sum_{i=1}^{p} f_{i}\left(X_{i}\right)
$$

Where $f_{i}\left(X_{i}\right)$ is a unary non-parametric function, and $E f_{i}\left(X_{i}\right)=0$.

The addictive semi-parametric model is built by adding the linear part to model (1). The model can not only reveal linear interaction between explanatory variables and explained variables but also keep the information of nonlinear effects, which is convenient to compare with pure linear models. The mathematical expression of the addictive semi-parametric model is as follows:

$$
E(Y \mid X)=\alpha+X^{\prime} \beta+\sum_{i=1}^{p} f_{i}\left(X_{i}\right)
$$

Where $X=\left(X_{1}, X_{2}, \cdots, X_{p}\right)^{\prime}, \beta=\left(\beta_{1}, \beta_{2}, \cdots, \beta_{p}\right)^{\prime}$.

Scholars brought many methods forward to estimate the semi-parametric addictive model (2). The most mainstream way is Backfitting presented by Buja,Hastie and Tibshirani(1989).Fan et.al(1998) proved the asymptotic property of $\hat{f}_{k}\left(x_{k}\right)$ as follows:

$$
\begin{aligned}
& \sqrt{n h_{k}}\left\{\hat{f}_{k}\left(x_{k}\right)-f_{k}\left(x_{k}\right)-\alpha-1 / 2 h_{k}^{2} \kappa_{2} f_{k}^{\prime \prime}\left(x_{k}\right)+o\left(h_{k}^{2}\right)\right\} \rightarrow N\left(0, v_{k}\left(x_{k}\right)\right) \\
& \text { There, } \kappa_{2}=\int u^{2} k(u) d u, v_{k}\left(x_{k}\right)=f_{k}\left(x_{k}\right)\left[\int k^{2}(u) d u\right], E\left\{\sigma^{2}\left(x_{k}, X_{-k i}\right) f_{-k}^{\prime \prime}\left(x_{-k}\right) / f^{\prime \prime}\left(x_{k}, x_{-k}\right) \mid X_{k i}=x_{k}\right\} .
\end{aligned}
$$

\section{Variables Selection and Data Sources}

\subsection{Variables Selection}

(1)Income Gap of Rural Residents. Gini coefficient is an standard indicator to measure the income gap and has been used in many literatures. Therefore, this paper also uses Gini coefficient 
as a measure of income gap. The calculation method is to divide rural residents into $n$ groups, in which $w_{i}, m_{i}, p_{i}$ respectively represent the ratio of total income in group $i$ to total income of the overall samples, per capita income and the population frequency, and ranks the average income of rural areas from small to big. The income gap of rural residents can be calculated by the following formula:

$$
\text { gini }=1-\sum_{i=1}^{n} 2 B_{i}=1-\sum_{i=1}^{n} p_{i}\left(2 Q_{i}-w_{i}\right)
$$

Where $\sum_{1}^{i} w_{i}=1, \sum_{i=1}^{n} p_{i}=1, Q_{i}=\sum_{1}^{i} w_{i}, B$ refers to the area enclosed by Lorenz curve and x-axis.

(2) Rural Financial Development. Financial scales and financial efficiency are the main measurement of financial development in existing literature. The scale indicator is commonly the radio of the financial institutions' loan scale to the economic aggregate. The efficiency indicator is the ratio of the financial institutions' loan scale to the assets scale. Similar to most of literature studying rural financial development, this paper adopts the scale indicator, considers the availability of the data and the comparability of the indicator, and combines the reality of China's rural finance, to indicate the development level of rural finance by the ratio of total rural financial assets and the rural GDP.

(3) Control variables. As the gap may be related to factors such as the development of rural economy, the rate of urbanization and so on, we cannot estimate the influence of financial development accurately if not control them. Therefore, similar to the main literature, this paper selects the following variables as control variables: The first is the level of rural economic development, which is represented by the ratio of rural GDP to the total rural population. Rural GDP is roughly equal to the sum of the added value of agriculture, forestry, animal husbandry and fishery and the added value of township enterprises. Though there may be some errors, the trends of the two are the same. The second is the level of urbanization, represented by the ratio of nonagricultural population to the total population. The third is the level of agricultural modernization, represented by the ratio of total power of agricultural machinery to cultivated lands in this paper. Besides the factors above, rural income gap is affected by geography, educational level, people's concept and so on. But we take them as unobserved factors here because of their lack of statistical data.

\subsection{Data Resource}

Taking the authenticity and completeness of the data into consideration, this paper adopts the data of 384 groups in 24 provinces and cities except Beijing, Yunnan, Jilin, Shandong, Hainan, Xinjiang and Tibet from 2000 to 2015. Firstly, the data of rural residents' income gap is calculated by the five-range grouped data on rural residents' per capita net income in the Statistical Yearbook of each province. The annual total loans of the rural credit cooperatives are directly obtained through Statistical Yearbook of China's Finance and Banking. The added value of farming, forestry, animal husbandry and fishery of different regions and township enterprises is obtained through Statistical Yearbook of each province. The level of agricultural modernization is worked out by using farm machinery production and agricultural acreage in China Agriculture Yearbook. The descriptive statistics of all variables is shown in table 1.

Table.1 Descriptive statistics of key variables

\begin{tabular}{|c|c|c|c|c|}
\hline Variable & Mean & $\begin{array}{c}\text { Standard } \\
\text { Deviation }\end{array}$ & Minimum & Maximum \\
\hline gini & 0.3089 & 0.0408 & 0.1486 & 0.4147 \\
\hline fd & 0.3751 & 0.2052 & 0.0108 & 1.1612 \\
\hline ngdp & 1.8393 & 3.0820 & 0.1331 & 20.8450 \\
\hline ncity & 0.3604 & 0.1649 & 0.1195 & 0.9003 \\
\hline ami & 0.6555 & 0.3762 & 0.1200 & 1.8926 \\
\hline
\end{tabular}




\section{Empirical Results}

\subsection{Model Specification}

According to the purpose of this paper, we use the semi-parametric additive model as empirical tools to capture the nonlinear impact mechanism of rural residents' income gap. The empirical model is set as follows:

$$
g i n i_{i t}=\alpha+\beta_{1} f d_{i t}+\beta_{2} n g d p_{i t}+\beta_{3} n c i t y_{i t}+\beta_{4} a m i_{i t}+f_{1}\left(f d_{i t}\right)+f_{2}\left(n g d p_{i t}\right)+f_{3}\left(n c i t y_{i t}\right)+f_{3}\left(a m i_{i t}\right)+\varepsilon_{i t}
$$

Where, $i, t$ represent the province and year respectively. $\beta_{i}$ are parameters to be estimated, and $f_{i}$ and $\varepsilon_{i}$ represent the unknown function and stochastic error respectively.

The semi-parametric additive model consists of linear and nonlinear parts. The linear part can study the influence of independent variables to dependent variables overall, which reveals the trend of effect. And the nonlinear part can find the changes of way of influence. We can judge how financial development and other factors tend to affect the rural income gap by the estimated results of the linear part in the model (3).

\subsection{Model Estimation Results}

Table 2 shows the estimated results of the linear part of the semi-parametric additive model. For comparison, the ordinary linear model is also estimated in table 2.

Table.2 The estimation results of linear parameters

\begin{tabular}{|c|c|c|c|c|c|c|c|c|}
\hline & \multicolumn{4}{|c|}{ linear model } & \multicolumn{4}{c|}{ linear part of addictive model } \\
\cline { 2 - 9 } & coeff & Std & t-value & p-value & coeff & Std & t-value & p-value \\
\hline const & 0.3198 & 0.0080 & 39.60 & 0.000 & 0.3205 & 0.0074 & 43.17 & $<0.0001$ \\
\hline fd & 0.0225 & 0.0106 & 2.10 & 0.036 & 0.0308 & 0.0098 & 3.13 & 0.0019 \\
\hline ngdp & -0.0002 & 0.0008 & -0.26 & 0.799 & 0.0026 & 0.0007 & 3.53 & 0.0005 \\
\hline ncity & -0.0462 & 0.0147 & -3.14 & 0.002 & -0.0545 & 0.0135 & -4.03 & $<.0001$ \\
\hline ami & -0.0035 & 0.0058 & -0.60 & 0.546 & -0.0124 & 0.0054 & -2.32 & 0.0211 \\
\hline
\end{tabular}

From table 2, it can be found that various coefficients' estimates of the linear part of addictive model all pass the significance test at 95\% confidence coefficient. However, the level of rural economic development and the level of agricultural modernization can't pass the test. And the influence on the level of economic development is opposite in the two models. From the comparison of linear models, biased and even false conclusions may be easily drawn if using pure linear models to do research. Table 3 describes estimates of the nonlinear part of the addictive model. It shows that variables pass the nonlinear test at the level of significance of $10 \%$, which means that each variable has a nonlinear impact on the income gap of rural residents markedly. As the stochastic error is the function of independent variables, the results estimated by ordinary linear model must be biased. It further proves the rationality of using the addictive model in the thesis.

Table.3 The test results of nonlinear parameters

\begin{tabular}{|c|c|c|c|c|}
\hline & fd & ngdp & ncity & ami \\
\hline statistics & 6.7186 & 7.5216 & 22.3499 & 11.3111 \\
\hline P-value & 0.0814 & 0.057 & $<.0001$ & 0.0102 \\
\hline
\end{tabular}

Figure 1 shows the estimated results of every variable function $f_{i}()$ in the model (1). The effect of variables to rural income gap appears two kinds of trends- - V shape and inverted $\mathrm{U}$ shape. 

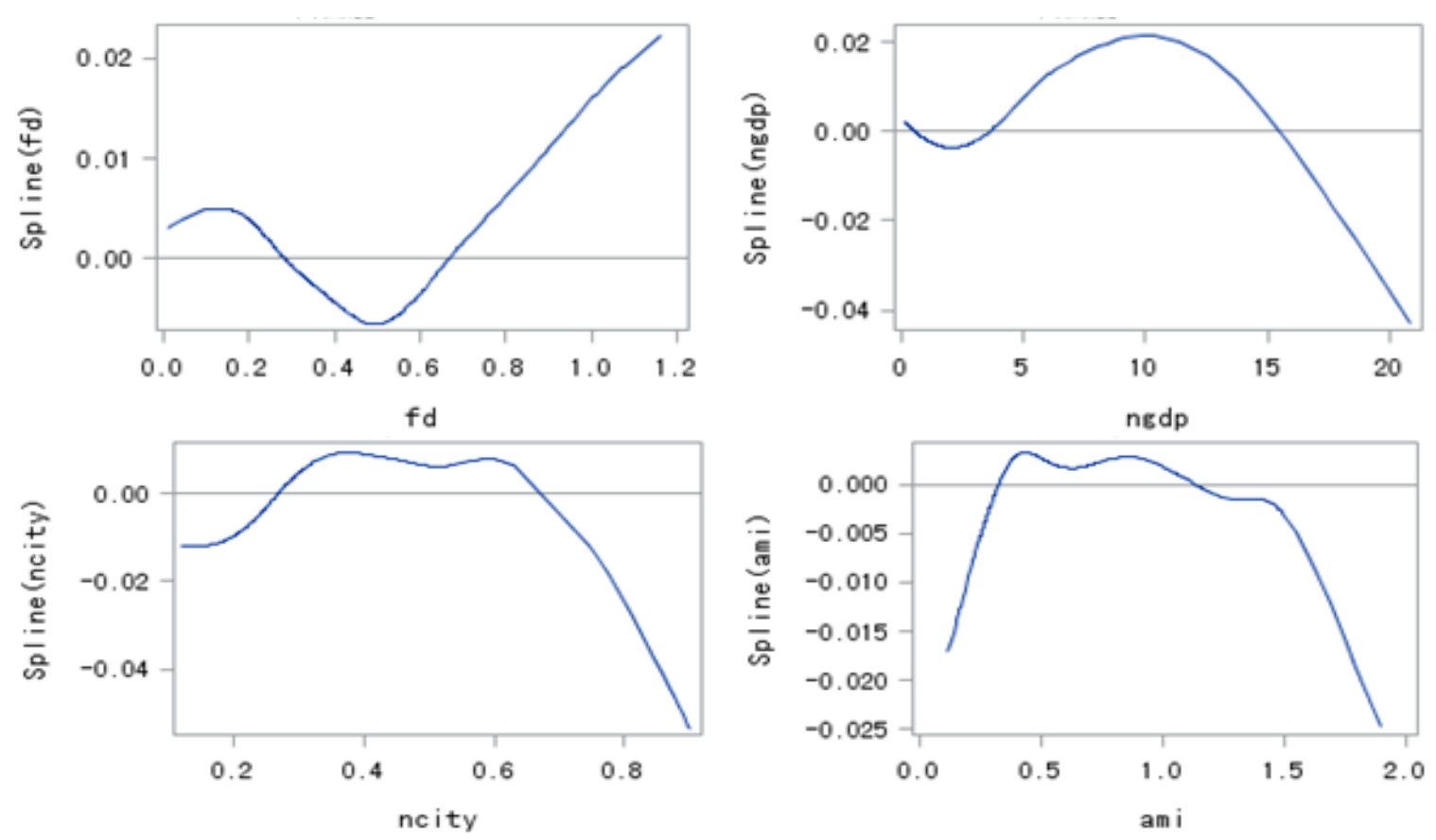

Figure.1 the nonlinear influence of rural residents’ income gap

\subsection{Discussion}

In table 2, the estimation of linear part of various variables has passed the significance test, which indicates that the imitative effect of linear model of influence factors on rural resident's income gap is the optimum. The coefficient of $f d$ in the model is 0.03078 , which indicates that the rural residents' income gap is subject to the positive impact on the developmental level of rural finance; and every $1 \%$ increase of rural finance shall result in the increase of 0.03078 percent points in the rural residents' income gap, which is considerably higher than the influence of rural economic developmental level. The coefficient of the level of agricultural modernization and urbanization are negative, which indicates that the increase of the level of agricultural modernization and urbanization can mitigate the increase of rural residents' income gap. Figure 1 is the nonlinear influence of different variables on the rural residents' income gap, which is the effective supplementation and perfection to the content unrevealed in the linear part of the model. According to the figure, the influence of $f d$ on rural residents' income gap is in ' $V$ ' shape; as most financial development level in existing rural area in China is in the initial stage, the financial market access is strict and the financial system is not perfect, which results in the fact that poor peasants cannot acquire the financing through the financial institution; however, the richer peasants can get the financing for investment based on their sufficient guarantee or good credit; in such actual conditions, the rural residents' income gap in China shall be increased with the development of rural finance, which is adverse to narrow the gap between the rich and the poor in China. As for $n g d p$, the influence of rural economic development level on the rural residents' income gap is in obvious 'inversed-U' shape. It indicates that in the initial period of rural economy growth, especially under the background of backward economy, the income inequality shall be enlarged with the development of rural economy, and the gap between the rich and the poor shall be enlarged as well. When the rural economy is developed to a high level, the employment of rural residents is improved, and the income level is increased largely; therefore, it is of great help to narrow the income gap of rural residents. As for the graphic display of ncity and ami, the influences of agricultural modernization level and urbanization level on rural residents' income are of 'inversedU' shape, which indicates that the urbanization level and agricultural modernization level are in the initial period; as the agriculture income takes the most part, and the machine is used relatively rare than the manpower, which results in the slow growth of rural residents' income; the income growth of rural residents is lower the that of non-agricultural population, thus the income gap is enlarged. When the urbanization level and agricultural mechanization level reach the high-level development 
state, then the income source of residents must be changed; and with the popularization of modern agriculture machines, the gap of labour productivity is narrowed, which is beneficial to reduce the income gap.

\section{Conclusion}

The paper is based on the panel data of 24 provinces and cities in China from 2000-2015 and makes use of the semi-parametric addictive model to analyze the relationship between the development of rural finance and the income gap of rural residents empirically. The results demonstrate the linear relation between these two facts is not simple. In terms of linearity, the development of Chinese current rural finance has positive relation with rural residents' income gap on average; while in terms of non-linearity, it presents ' $V$ ' shape linear relationship. This indicates that positive relation between these two facts tends to be weaker with further development of rural finance. However, this isn't entirely consistent with findings of domestic scholars. In addition, the research finds that other factors also affect rural residents' income, for instance, agricultural modernization and urbanization level have prominent inverted-U-shaped non-linear relation with the income gap of rural residents.

\section{Acknowledgments}

This paper is supported by the Education Research Project of Young and Middle-aged Teachers of Fujian Province (No. JAS150251) and Fujian Science and Technology Fund (No. 2016J05172) .

\section{References}

[1] Aghion, P., Bolton, P. (1997) A Theory of Trickle-Down Growth and Development. Review of Economic Studies, 64(2):151-72.

[2] Banerjee, A., Newman, A. (1993) Occupational choice and the process of development, Journal of Political Economy, 101(2): 274-298.

[3] Galor, O., Zeira, J. (1993) Income distribution and macroeconomics. Review of Economic Studies, 60 (1): 35-52.

[4] Greenwood, J., Jovanovic, B. (1990) Financial development, growth and the distribution of income. Journal of Political Economy, 98(5): 1076-1107.

[5] Knight, J., Song, L. (1993) The spatial contribution to income ine-quality in rural China [J]. Cambridge Journal of Economic, 63(17): 195-213.

[6] Matsuyama, K. (2000) Endogenous inequality. The Review of Economic Studies, 2000, 67(4): 743-759.

[7] Morduch, J., Sicular, T. (2002) Rethinking inequality decompo-sition, with evidence from rural China[J]. The Economic Journal, 89(112): 93-106.

[8] Stone, C. (1985) Additive regression and other nonparametric models. Annals of Statistics, 13( 2) : 689-705.

[9] Townsend, R., Ueda, K. (2006) Financial deepening, inequality and growth: a model-based quantitative evaluation. Review of Economic Studies, 2006, 73(1): 251-293.

[10] Lu, X., Li, P., Chen, G. (2013) Chinese Research Perspectives on Society in 2013. Social Science Academic Press. 